\title{
European solidarity patterns during a pandemic
}

\author{
Zsófia S. Ignácz (ignacz@soz.uni-frankfurt.de) \\ Goethe University Frankfurt, Germany \\ Alexander Langenkamp (langenkamp@soz.uni-frankfurt.de) \\ Goethe University Frankfurt, Germany
}

In recent years, a variety of crises have made European solidarity a salient topic. Amidst the COVID-19 pandemic, European solidarity yet again came to the fore in spring 2020. The pandemic has burdened European citizens financially, socially and physically; likewise, EU member states have struggled under the economic and social pressure. Consequently, European solidarity will likely be affected by the pandemic as well. This paper uses a primary dataset collected in Germany between 27 March and 26 April 2020 to investigate individual willingness to extend solidarity transnationally. Overall, the paper contributes to the literature in three important respects. First, it introduces new attitudinal questions about supporting Europeans suffering from the novel coronavirus and about European healthcare institutions struggling to care for COVID-19 patients. Second, the study uses confirmatory factor analysis to investigate how attitudinal questions about support for European citizens and healthcare institutions under the COVID-19 pandemic relate to other forms of European solidarity. Finally, the study provides new insights into the underlying structure related to European solidarity and extends our overall understanding of what European solidarity entails.

Keywords: European solidarity, COVID-19, generalized attitudes

\section{Introduction}

In spring 2020, the COVID-19 pandemic reached Europe. Since then, European societies have found it difficult to handle the resulting crisis: the pandemic has strained European healthcare systems and propelled economic downturns (Coibion et al., 2020; Khurshid \& Khan, 2020; Saunders, 2020). Some initial studies have consequently shown growing levels of cultural and educational inequality (Jæger \& Blaabæk, 2020). Likewise, the aftermath has left Europeans in vulnerable labour market positions and led to hardships of various kinds: economic (Bauer \& Weber, 2020), social (Kreyenfeld et al., 2020; Möhring et al., 2020; Sibley et al., 2020; Wachtler et al., 2020), and psychological (Czymara et al., 2020; Pfefferbaum \& North, 2020).

Yet, despite the rapidly accumulating number of studies investigating the pandemic's impact on society, little is known about how it has affected attitudes towards European (institutionalized) solidarity (for a recent assessment of informal solidarity, see Voicu et al., 2020). Nevertheless, there are good reasons for connecting the issues of European solidarity and the pandemic and seeking to understand their relationship. For one thing, both are phenomena affecting transnational societies. Moreover, learning about attitudes 
towards European solidarity is important both at a practical and theoretical level. In such trying times, are Europeans ready to extend their support beyond their national borders? Political responses to the COVID-19 pandemic were initially nationally oriented and focused on rolling back transnational practices (Anderson et al., 2020; Sülün, 2020). However, as time went on, policymakers broadened their strategies to provide extensive transnational support. For instance, EU member states openly addressed questions of European solidarity (also in this special issue: Wallaschek \& Ziegler) and they took a number of measures in response: the European Solidarity Fund was made available to member states (European Parliament, 2020a), the Next Generation EU package was introduced (European Commission, 2020a European Parliament, 2020b) and temporary unemployment reinsurance schemes were implemented (Schmid, 2020). Likewise, there were prominent examples of transnational bilateral cooperation to help national healthcare systems crippled by the number of hospitalized individuals (European Commission, 2020b; Tidey, 2020). Yet, there is no information on how European citizens viewed these transnational measures and the underlying principle: extending help to others within Europe during the COVID-19 pandemic.

The concept of citizens' attitudes towards European solidarity is a multidimensional one and covers a broad spectrum of topics, such as attitudes to fiscal solidarity, to welfare solidarity or to specific social policies related to various issues. European solidarity related to the COVID-19 pandemic thus joins the ranks of other forms of European solidarity and expands our understanding of it. Moreover, information about how European solidarity in this new context (i.e. the pandemic context) relates to other forms of European solidarity deepens our understanding of the concept. Such knowledge is especially helpful to validate and adjust models that were proposed on European solidarity prior to the pandemic. Hence, at the theoretical level, this knowledge is valuable as it offers insights that may be used by future studies investigating European solidarity in general and improves existing conceptualizations of European solidarity.

In line with this reasoning, this study provides empirical insights on European solidarity related to the COVID-19 pandemic and its connection to other forms of solidarity. It utilizes data from a survey fielded in March and April 2020 in Germany. At this time, Germany was experiencing its first pandemic-related lockdown. The paper investigates how different forms of European solidarity relate to one another by employing confirmatory factor analysis. It identifies the factor structure that best describes the empirical data at hand. In doing so, it also offers some theoretical insights into European solidarity in general.

The following section describes the theoretical considerations that help embed European solidarity related to the COVID-19 pandemic into the existing research focusing on European solidarity. It highlights prominent dimensions that structure different forms of solidarity and derives corresponding hypotheses for empirical verification. The third section presents the research design and analytical steps. The fourth section reports the corresponding results. The final section concludes and critically discusses the insights gained.

\section{Patterns in European solidarity}

European solidarity refers to a variety of behaviours and attitudes expressed by citizens about transnational and supranational support within the European Union and/or Europe. For instance, European solidarity might be expressed by favouring the provision of fiscal support for European member states or by supporting measures that may lead to the development of a European welfare state system. At the same time, European solidarity can refer to either a general notion of support or support of specific policies implemented at the European level (Ignácz, 2019). For the purposes of this study, we focus exclusively on generalized attitudes. They are less likely to be altered by media coverage and personal 
circumstances and reflect how the general public relates to the principles underlying European solidarity.

Overall, there is a steadily growing body of literature focusing on generalized attitudes towards European solidarity (Baute et al., 2018; Ciornei \& Recchi, 2017; Díez Medrano et al., 2019; Ferrera \& Pellegata, 2019; Gerhards et al., 2019a; Hooghe \& Verhaegen, 2017). Most research has singled out one form of European solidarity (for instance, attitudes towards fiscal solidarity or towards migration within the European Union) and analysed the chosen form in depth, i.e. it has looked at what explanatory factors are connected to that particular form of European solidarity. However, when research has focused on a single form of European solidarity in isolation from other forms, it is often difficult to assess how attitudes towards different forms of European solidarity interrelate with each other. This problem is exacerbated whenever a new form of solidarity is introduced into the scientific discourse, for example, European solidarity related to the COVID-19 pandemic.

To date, conceptual frameworks that postulate a universe of interrelated forms of European solidarity have been rare. Few studies have addressed the fact that multiple forms of European solidarity exist (Baute et al., 2018; Ciornei \& Recchi, 2017; Genschel \& Hemerijck, 2018; Gerhards et al., 2019a; Reinl, 2020). An even smaller set of papers has assessed the relation between the different forms of solidarity or identified an underlying structure that systematically orders the different forms of European solidarity.

According to some scholars, we can theoretically structure forms of European solidarity according to several dimensions. One such dimension centres on the triggers for extending solidarity to others in the European social space. For instance, an event such as a natural disaster might prompt individuals to provide support beyond the nation state. Genschel and Hemerijck (2018) have shown that support for international solidarity is greatest when the issue is externally caused, like a natural disaster, but lowest in cases of excessive national debt; however, they did not provide an in-depth analysis of support rates. Like Genschel and Hemerijck, Gerhards and colleagues (2019a) differentiated European solidarity according to triggers. The authors stressed that recent EU crises have been the main triggers for European solidarity. These crises made the topic salient among the general population. They provided the contexts and reasons for individuals (i.e. Europeans and European member states) to express their support for extending solidarity to certain recipients, thereby anchoring European solidarity in particular themes.

The study by Gerhards and colleagues is notable for several reasons. First, it used a systematic conceptual framework and introduced four forms of European solidarity. Each of the forms of European solidarity is associated with a recent EU crisis. Second, Gerhards et al. (2019a) employed a benchmark system to empirically validate the existence and strength of each form of European solidarity. Yet, despite the complex framework developed for European solidarity, Gerhards and colleagues only investigated the four forms of European solidarity as singular phenomena, isolated from one another.

A second dimension that scholars (Baute et al., 2018; Ciornei \& Recchi, 2017) have identified as structuring forms of European solidarity concerns the type of actor that receives support when extending solidarity. While both sets of authors in this field differ in the terminology they use and how they operationalize forms of European solidarity, they all differentiate between two forms of European solidarity: transnational solidarity (or interpersonal solidarity) and international (or member-state) solidarity. Transnational solidarity means extending support to Europeans living in other countries (i.e. individual actors), while international solidarity means extending help to other countries (i.e. collective actors). Baute and colleagues (2018) showed that these two forms of European solidarity are conceptually distinct and Ciornei and Recchi (2017) highlight that the determinants of transnational and international solidarity often do not overlap empirically. 
Lastly, a third dimension that, according to scholars, structures forms of European solidarity relates to the guiding principle behind extending solidarity to others. This differentiation is well-known in the research on national welfare states. The two main goals of welfare states are (1) to provide protection against and compensation for social risks (e.g. the risk of being sick, unemployed or old) (Pettersen, 1998), and (2) to reduce social inequality via redistributive policies (Roller, 1998). The guiding principle behind the former is risk sharing, aid is extended on a one-off basis (with the exception of old-age pension) and the aim is to assist in an emergency. The guiding principle behind the latter goal is redistribution, aid is provided continuously over the long term and the aim is to change society structurally. This differentiation has spilled over into the research field on European solidarity. Risk-sharing European solidarity means extending support within the European social space to shield recipients from the aftermath of certain emergencies. In contrast, redistributive European solidarity aims to reduce existing structural differences in the long term. Correspondingly, Reinl (2020) has isolated these two forms of European solidarity by running a confirmatory factor analysis on an international survey fielded in Austria, Germany and Greece. Reinl's findings are especially important, as they show that such structures are not unique to a certain country but is equivalent across countries.

Overall, there is a lack of both research and evidence about the structure underlying European solidarity. The current state-of-the-art research suggests that European solidarity could be structured along any of the three dimensions above. This makes it difficult to anchor a potentially new iteration of European solidarity in previous discussions. Empirically examining how European solidarity related to the COVID-19 pandemic fits with other forms of European solidarity gives us clues about European solidarity that go beyond the context of the pandemic and also hint at the underlying structure for different forms of European solidarity. Thus, in this paper, we focus on the above-described dimensions: the trigger for support, the type of actor and the guiding principle behind support and consider how European solidarity related to the COVID-19 pandemic can be placed in each of the three dimensions.

\subsection{European solidarity related to the COVID-19 pandemic: the newest form of European solidarity?}

The COVID-19 pandemic is a novel situation for Europeans and has presented the EU with unique challenges. Moreover, it has raised the question of whether European solidarity related to the COVID-19 pandemic is a new form of European solidarity or whether it can be subsumed under one of the existing forms. The pandemic shares similarities with other recent crises in the EU, but it also has some unique attributes. For instance, like the Great Recession and the sovereign debt crises that plagued many EU member states during 2008-2010, the pandemic has affected European member states unequally and forced different groups of individuals into precarious circumstances. Yet, we can identify major differences compared to previous crises. While inequalities in previous crises mapped onto EU member state's geographical or economic centre-periphery positions, inequalities in the pandemic do not. Furthermore, the pandemic has the potential to unify Europeans: the largely shared experience of personal mobility restrictions, school shutdowns and transformed workplace environments have connected Europeans in a manner untypical of other crises. These characteristics have helped shape expectations related to European solidarity during the pandemic. In the following, we will present arguments that can enable us to understand how European solidarity related to the COVID-19 pandemic fits with other forms of European solidarity. Given the limited empirical knowledge available about the underlying structure of the forms of European solidarity, each of the competing arguments are equally plausible. The key task of the empirical analysis is to assess whether one of the arguments is more plausible than the others. 
One argument suggests that the COVID-19 pandemic could be a new trigger for European solidarity. Following the logic of Gerhards and colleagues (2019a), the pandemic could create a new context for extending solidarity both to European citizens and EU member states. As such, we could plausibly expect this to be distinct from other forms of European solidarity. Based on this, we can conclude that if solidarity related to the COVID-19 pandemic can be clearly distinguished from other forms of solidarity, then the trigger for solidarity plays a decisive role in structuring European solidarity.

H1. Forms of European solidarity are structured according to triggers for extending solidarity.

Alternatively, European solidarity related to the COVID-19 pandemic may not necessarily constitute a new form of European solidarity. Instead, it could be subsumed under existing forms of European solidarity. After all, we can identify mechanisms that resemble those of other forms of European solidarity. For instance, ensuring the right to access decent healthcare is a well-known form of European solidarity; becoming sick with the novel coronavirus is simply a more specific reason to need high-quality healthcare. Moreover, extending financial support to countries facing economic hardship is another way to offer European solidarity. The reason why a given country needs economic aid might not be relevant and, hence, extending solidarity because of a banking crisis or a pandemic could be viewed as interrelated. In short, solidarity with financially troubled, lockdown-hit EU member states could be akin to fiscal solidarity. These thoughts are also underlined by Gerhards (2020), who draws on evidence of high support rates for European fiscal and welfare solidarity in previous crises to argue that similar positive responses from Europeans in the wake of the current pandemic should be expected. Therefore, it is reasonable to assume that attitudes towards European solidarity related to the COVID-19 pandemic would fit with these existing forms of European solidarity. This argument relates to the structuring of European solidarity by the type of actor. The pandemic is affecting both individuals and collective actors, so European solidarity related to the COVID-19 pandemic may need to be extended to both individuals and collective actors. Supporting measures to help COVID-19 patients means showing solidarity with individuals, while solidarity with EU member states dealing with high infection rates and economic difficulties resulting from the pandemic means showing solidarity with collective actors. So, if solidarity related to COVID-19 can be subsumed under the existing dimensions of welfare and fiscal solidarity respectively, then the type of actor receiving solidarity might impact the underlying structure of European solidarity.

H2. Forms of European solidarity are structured according to the type of actor that the recipient is.

Finally, in broad terms, the pandemic gives reason to extend short-term solidarity to others in vulnerable positions and is dictated by a risk-sharing principle, i.e. by the fact that individual and collective actors face a state of emergency due to the pandemic. As far as individuals are concerned, supporting the right to access decent healthcare and receive treatment is a way of extending solidarity with people suffering a personal health emergency. Second, as far as collectives are concerned, supporting EU member states in financially difficult positions when their healthcare systems are facing economic difficulties due to pandemic lockdowns is a way of extending solidarity to member states in an economic emergency. Extending help in these circumstances means individuals are ready to collectively share the risks of the pandemic. From this, we can conclude that if forms of European solidarity, such as European welfare solidarity and European fiscal solidarity and solidarity related to the COVID-19 pandemic all fit together, then the guiding principle decisively structures European solidarity. 
H3. Forms of European solidarity are structured according to the guiding principle for extending solidarity.

\subsection{Salient structure across diverse social groups}

Lastly, if we wish to claim that different forms of European solidarity are structured according to one particular dimension, it is important to examine whether the identified structure is salient across diverse social groups. Unfortunately, we currently lack information on how European solidarity is structured across social groups and whether we can expect differences. To assess whether the identified structure is salient, we can only look at empirical studies that focus on how the level of support for different forms of European solidarity diverges. Thus, if we observe that the structure of European solidarity is the same across social groups despite the fact that we would expect different levels of support for European solidarity, this indicates that the structure is salient. To this end, we wish to identify one final aspect, namely the most prominent social groups that exhibit distinct support for (or disapproval of) European solidarity.

Psychological studies show that the social framing of prosocial behaviour has a stronger reinforcing effect for women compared to men (Espinosa \& Kováríík, 2015). Furthermore, women still hold disadvantaged labour market positions and more often rely on a strong welfare system in all European countries (Dernberger \& Pepin, 2020; Witkowska, 2013). The COVID-19 pandemic has reinforced this pattern of gender inequality on the labour market (Alon et al., 2020; Collins et al., 2020). Education is a major predictor of socioeconomic status and may also be a factor influencing attitudes towards European solidarity. Studies show that higher education exerts a strong influence on welfare state preferences and on solidarity with migrants (Hainmueller \& Hiscox, 2007; Häusermann et al., 2015; Mau \& Burkhardt, 2009). Others have identified personal identification with Europe as an important predictor of European solidarity (Ciornei \& Recchi, 2017). As argued by Ciornei and Recchi, further studies showed that identification is positively associated with supporting a supranational fiscal government and a Europeanization of social policy (Kuhn \& Stoeckel, 2014; Mau, 2005). Finally, studies on generational differences in attitudes have highlighted the role of birth cohort for attitudes towards European solidarity. Most notably, some authors have identified substantial differences regarding fiscal solidarity between generations (Daniele \& Geys, 2015). These scholars note that younger generations seem to favour the European project and be more open to fiscal integration than older generations in creditor countries in the Eurozone crisis.

If one specific structure prevails across social groups despite their different levels of support for European solidarity, we can expect that the interrelatedness of different forms of European solidarity (including European solidarity related to the COVID-19 pandemic) to be salient.

H4. The dominant structure of European solidarity does not vary across social groups.

\section{Data and methods}

In order to investigate the research question at hand, we utilized an online survey conducted between 27 March and 26 April 2020 in Germany. The survey started shortly after the German government introduced nationwide social distancing policies: most stores, public venues, schools and childcare facilities were ordered to close. At the time, there was wide media coverage of the situation in Germany and other EU member states. Hence, the survey takes advantage of the social situation prevailing in the EU in the spring of 2020 and the salient debate on European solidarity. The survey was advertised in a press release by Goethe University Frankfurt, which was promoted on the university's Facebook page and on official Facebook pages of German municipalities. Furthermore, the study was 
shared on the Psychologie Heute website. After listwise deletion, this sampling strategy resulted in 1951 respondents. Data from the online survey are stored at the GESIS Data Archive (Langenkamp, 2020).

Women dominated the sample, making up roughly 74 percent. For both genders, younger individuals with higher educational degrees were oversampled. For this reason, the data cannot be used to draw any generalizable conclusions about the German public's support for European solidarity. However, as the study primarily sought to assess the structure within which forms of European solidarity relate to one another, the sample's lack of representativeness is not a fundamental issue. The study did not aim to draw any generalized conclusions for the German population. Furthermore, it tested for the robustness of the results by looking at whether the findings were sensitive to selection effects relating to gender, level of education, identity, and cohort. Still, as in all convenience samples, the findings need to be replicated with other representative datasets for validation purposes (Peterson \& Merunka, 2014).

\subsection{Operationalization}

The framework introduced by Gerhards and colleagues (2019a) provides the best foundation for empirically measuring attitudes towards European solidarity related to the COVID19 pandemic and other forms of European solidarity. This study theoretically structured European solidarity by triggers (i.e. crises) and adopted a multidimensional approach that covered many forms of European solidarity. This multidimensional approach is useful for understanding where European solidarity related to the COVID-19 pandemic fits with other forms of European solidarity. Furthermore, the use of a thirteen-country survey means the findings could be considered cross-nationally validated. Thus, this approach serves as a starting point for the development of the items to measure attitudes towards European solidarity.

The online survey included an item battery focusing on citizens' attitudes towards European solidarity. The items are 5-point Likert scales. The lowest value (1) meant respondents did not agree with the statement, while the highest value (5) meant they agreed totally with the statement. In particular, the survey incorporated established items like welfare state solidarity and fiscal solidarity along with some new items, which contextualized the COVID-19 pandemic. The survey thus included items associated with different triggers. It also included items that captured the type of actor - individual or collective - to which solidarity is extended. Lastly, some items examined attitudes towards risk-sharing solidarity - items that refer to redistributive solidarity were excluded. See Table A1 in the Appendix for a complete overview of the items and their relations to the three theoretical dimensions.

The established items were taken from the Transnational European Solidarity Survey (TESS) (Gerhards et al., [unpublished]), as these items have been validated in thirteen EU countries. The wording of the established items reads as follows (abbreviations in the squared brackets refer to how the items are identified in the figures).

- The European Union should guarantee a decent standard of living for the elderly in the EU. [ELDER]

- The European Union should guarantee access to healthcare for everyone in the EU. [SICK]

- The European Union should guarantee a decent standard of living for the unemployed in the EU. [UNEMP]

- In times of crisis, EU member states facing severe economic difficulties should receive financial help. [ECON] 
New items linking European solidarity to the COVID-19 pandemic were formulated based on these established items. The new items followed a similar grammatical syntax and included as few modifications as possible. Essentially, they specify the reason why support would need to be extended - because of the COVID-19 pandemic. In total, three items were fielded.

- The European Union should guarantee access to healthcare for everyone in the EU who is ill because of the novel coronavirus. [COV-SICK]

- During the coronavirus pandemic, every member state of the European Union is responsible for the spread of the virus in their own country. [COV-NATR]

- During the coronavirus pandemic, EU member states should support each other beyond financial means. [COV-ECON]

The second to last item in this list aimed to capture a lack of European solidarity, as it emphasized how each member state is responsible on its own. Thus, not agreeing with this item would reflect more support for European solidarity and should relate negatively to other items. Hence, this item measures European solidarity indirectly. For an overview of the descriptive statistics for each of the items, see Table 1.

Table 1: Descriptive statistics

\begin{tabular}{|c|c|c|c|c|}
\hline Variable & $\begin{array}{l}\text { Mean/ } \\
\text { Pct. }\end{array}$ & $\begin{array}{l}\text { Std. } \\
\text { Dev. }\end{array}$ & Min. & Max. \\
\hline \multicolumn{5}{|l|}{ European solidarity } \\
\hline EU: ensure decent standard of living for elderly & 4.076 & 1.022 & 1 & 5 \\
\hline EU: guarantee healthcare for people in the EU & 4.483 & 0.824 & 1 & 5 \\
\hline $\begin{array}{l}\text { EU: ensure decent standard of living for unem- } \\
\text { ployed }\end{array}$ & 3.871 & 1.084 & 1 & 5 \\
\hline $\begin{array}{l}\text { EU: guarantee healthcare for people infected } \\
\text { with coronavirus }\end{array}$ & 4.451 & 0.871 & 1 & 5 \\
\hline $\begin{array}{l}\text { During crisis support EU member states with fi- } \\
\text { nancial aid }\end{array}$ & 3.992 & 0.952 & 1 & 5 \\
\hline $\begin{array}{l}\text { All member states responsible for spread of the } \\
\text { virus in their own country }\end{array}$ & 3.932 & 1.114 & 1 & 5 \\
\hline $\begin{array}{l}\text { During the pandemic member states should } \\
\text { support each other beyond financial means }\end{array}$ & 4.377 & 0.817 & 1 & 5 \\
\hline \multicolumn{5}{|l|}{ Gender } \\
\hline Male & 0.254 & - & - & - \\
\hline Female & 0.746 & - & - & - \\
\hline \multicolumn{5}{|l|}{ Education } \\
\hline Secondary or less & 0.385 & - & - & - \\
\hline Tertiary & 0.615 & - & - & - \\
\hline \multicolumn{5}{|l|}{ Year of birth } \\
\hline After 1990 & 0.307 & - & - & - \\
\hline Between 1961 and 1990 & 0.597 & - & - & - \\
\hline Before 1961 & 0.097 & - & - & - \\
\hline \multicolumn{5}{|l|}{ Identification } \\
\hline Primarily German & 0.665 & - & - & - \\
\hline Primarily European & 0.208 & - & - & - \\
\hline \multirow[t]{2}{*}{ Neither German/European } & 0.128 & - & - & - \\
\hline & 1951 & & & \\
\hline
\end{tabular}

Source: Own calculations. Link to data: https://doi.org/10.7802/2033.

Note: Item wording is shortened in the table. Respondents with primary and secondary level of education were pooled together because there were few respondents with primary level education $(\mathrm{N}=53)$. 


\subsection{Analytical strategy}

We employed confirmatory factor analysis (CFA) to assess the dominant structure underpinning European solidarity. CFA is a theory-driven method to determine underlying, latent constructs that cannot be measured directly (Brown \& Moore, 2015). In particular, the analysis used reflective measurement models to determine whether the items selected from the dataset load on a corresponding latent construct, i.e. whether the items represented one factor dimension or more. This method allowed us to assess whether a certain structure prevailed within our items (Lewis, 2017). For example, if different items measuring European solidarity were grouped according to two different factor dimensions, this would suggest that they were distinct from each other and would allow us to identify two forms of European solidarity.

CFA is based on the correlation matrix of the items included in the models (see Appendix Table A2 for correlation matrix of the items), but it also considers the relevance of measurement errors for each item. CFA allowed us to test whether a certain way of grouping items corresponded to any of our theorized divisions. Indeed, our hypothesis testing sought to assess whether the theorized model was consistent with the empirically observed model. CFA provided us with a set of goodness-of-fit measures, which stem from the log-likelihood value of the maximum likelihood estimation and the nonparametric Chisquare value (Brown, 2015). The global fit indices - CFI, RMSEA and SRMR - further assisted in assessing the estimated models with cut-off points (following the guidelines from Hu \& Bentler, 1999). A common approach is to start out with an "unstructured" CFA (where all items load on to one factor dimension) and then assess whether the model fits improve if the items are grouped together in different configurations with more than one factor dimension.

Once we had assessed the overall structure of the items, we also tested whether the structure was salient across social groups. To this end, we split the sample according to gender (men and women), level of education (secondary level or lower and tertiary), identity (European or German) and cohort (born before 1961, 1961-1990, and after 1990). (For an overview of the descriptive statistics for the grouping variables, see Table 1). Then, we performed multiple group CFA to assess whether the factor weights of the items can be regarded as equal across all groups. Here, the chi-square difference test was employed to compare different factor solutions in the multi-group comparison (Kline, 2011), while also considering the unstandardized factor weights (Cheung \& Rensvold, 2002).

The dataset was prepared in Stata 16 and the analysis was conducted in R (R Core Team, 2019) and Mplus (Muthén \& Muthén, 1998-2019). The R package MplusAutomation (Hallquist \& Wiley, 2018) was used for the CFA; the semPlot package (Epskamp, 2019) was used to depict the measurement models and ggplot2 (Wickham, 2016) was used to visualize the support rates.

\section{Results}

Before investigating the structure of European solidarity, we begin in this first section by giving a brief overview of the support rates for each item included in the analysis. Figure 1 captures the prevalence of the responses to the seven items on European solidarity (four previously used and three new items, operationalized to apply to the COVID-19 pandemic). The graph shows support rates: the rate of respondents who agreed with the statements in the items (i.e. "tend to agree" or "fully agree"). The height of the bar provides the total support rate for each item, while the division within each bar reflects the rates per response category.

The results of previous studies (Ferrera \& Pellegata, 2019; Gerhards et al., 2019a; Gerhards et al., 2019b; Vasilopoulou \& Talving, 2020) suggested that support rates for European solidarity were well over 50 percent, although they vary greatly across studies depending on 
the operationalization of European solidarity. The results of the current survey also indicated strong support for European solidarity. For every item directly measuring European solidarity, the support rates showed approval by an overwhelming majority. Very high support rates were evident for three items; close to 90 percent of the respondents favoured extending solidarity to Europeans who are sick in general, to those who are infected with the novel coronavirus more specifically, and to EU member states that are struggling financially due to the COVID-19 pandemic. Support for extending solidarity to elderly Europeans was about 10 percentage points lower. The least supported items asked about extending solidarity to unemployed Europeans and to EU member states facing financial difficulties due to a sovereign debt crisis. These rates were at about 70 percent. However, all of these support rates are high overall and suggest positive attitudes to European solidarity. Finally, note that the item on national responsibility stood out from other items: it had moderate support rates. About 70 percent of respondents believed that EU member states are responsible for preventing the spread of the virus within their own countries.

Figure 1: Support rates for European solidarity

100

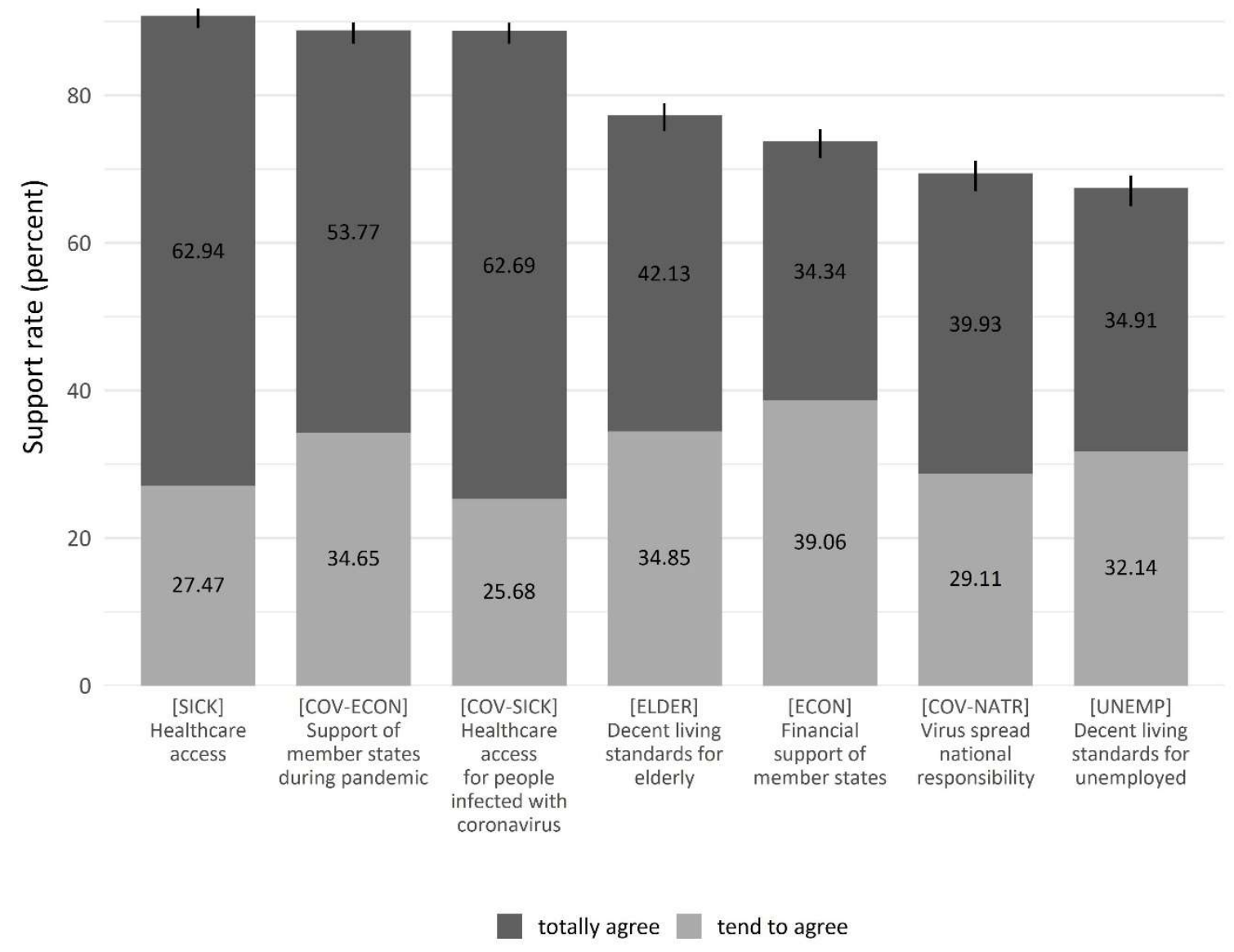

Source: Own calculations. Link to data: https://doi.org/10.7802/2033.

Notes: $\mathrm{N}=1951$. Error terms depict $95 \%$ confidence intervals for overall support rates.

What is noteworthy is that the support rates for being sick in general or being sick with the novel coronavirus were similar. In contrast, there were larger disparities in support rates for helping EU member states during the COVID-19 pandemic and helping EU member states in a sovereign debt crisis. This could potentially reflect the salience of the issues related to COVID-19 but may also hint that individuals are more sceptical about extending solidarity to collective actors. The salience of the pandemic is also clear when looking at 
how the rates of those who "fully agree" with pandemic-related European solidarity measures compared to the rates of those who only "tend to agree" with the statements. The differences between the two response categories were even more evident for the non-pandemic items.

\subsection{Structure of European solidarity}

Beyond looking at descriptive statistics on support rates, this study principally aimed to identify the underlying structure that connects items on European solidarity and to assess how items related to the COVID-19 pandemic are linked to established measures of European solidarity. To that end, we systematically went through theoretically derived factor solutions to assess which solution best fit the survey data. To investigate how forms of European solidarity interrelate (including European solidarity related to the COVID-19 pandemic), we entered all seven items into the CFA to assess their relation to each other. We tested different configurations of the items (i.e. factor solutions) that corresponded to our hypotheses (See Table 2 for an overview of the tested factor solutions).

In the theoretical section of the paper, we argued that the forms of European solidarity may be structured according to three different dimensions. This translated into roughly three different configurations for the CFA models. The first dimension distinguished forms of European solidarity based on triggers. This would mean that items related to the COVID19 pandemic should constitute a distinct factor from other items. Furthermore, the established items corresponded to the concepts of fiscal and welfare state solidarity, so they should also be distinct factors in the model. This would result in a three-factor solution. The second dimension distinguished forms of European solidarity according to the type of actor that needs help. Correspondingly, items referring to extending European solidarity to individuals were regarded as a distinct factor, as were items measuring extending help to European member states (or the lack thereof). Lastly, the third dimension according to which forms of European solidarity may be distinguished was the guiding principle behind solidarity. Since all of the items included in the analysis referred to short-term assistance, this would mean defining a unidimensional CFA model (See Figure 2 for an overview of the estimated models). 
Figure 2: Overview of theoretical CFA models
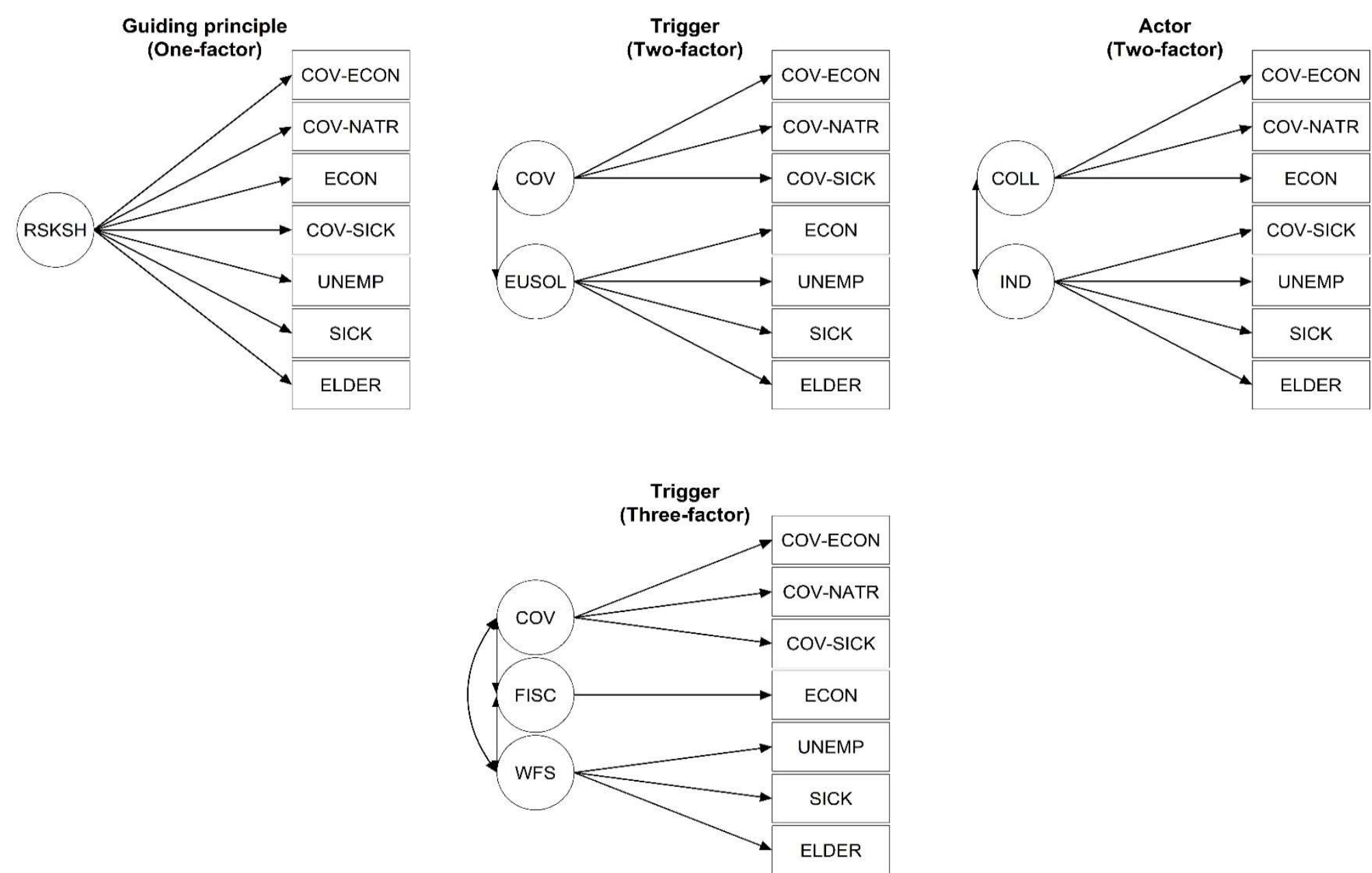

Source: Own depiction. 
Following the conventional CFA approach, we first tested whether all items loaded on the same factor dimension - that is, we tested whether the item structure reflected that European solidarity is structured by the principle guiding the extension of solidarity and whether all items loaded on the factor dimension for risk-sharing solidarity. However, this one-factor solution had a very bad fit. None of the established incremental fit indices reached the established cut-off values. Thus, we can discard the argument that European solidarity is structured according to the guiding principle behind solidarity. The next step was to assess whether other factor solutions better fit the single-factor solution. To this end, we split the items according to the two other dimensions to see which solution resulted in a more noticeable improvement in model fits. Splitting the items based on the triggers meant first splitting the factors to distinguish the established items and the new items related to the COVID-19 pandemic and then splitting for each trigger separately. Both the two- and three-factor-solution indicated a poor fit. Allocating the items based on the trigger for solidarity led to a very small improvement compared to the single-factor solution. In fact, the factors identified by the CFA were highly correlated, which again indicated that structuring based on the trigger dimension was not viable. This suggests that the new items do not constitute a distinct form of European solidarity. In contrast, they likely fit with existing forms of European solidarity. To this end, we also split the items according to the type of actor in a two-factor solution. The measurement model that distinguished items depending on whether they concerned individual and collective actors showed a significant improvement in the model fit. TLI, CFI and SRMR all exceeded the desired cut-off points. In fact, the solution that divided the actors based on the type receiving solidarity exhibited the best fit of all the models. Yet, while this two-factor solution yielded the most acceptable results, the RMSEA (0.116) was still far from the established threshold of 0.05 . While a logical solution would have been to exclude the items with low standardized factor values (COV-NATR), this did not improve the model fit. Instead, we divided the factor capturing items about solidarity towards individuals further into two factors: healthcare solidarity and social security solidarity (i.e. solidarity with vulnerable groups). This three-factor model once again significantly improved the fit. Table 2 reflects the model fits for these described models.

Table 2: Overview of CFA Models

\begin{tabular}{lccccccc}
\hline \multicolumn{1}{c}{ Model } & $\chi^{\mathbf{2}}$ & df & BIC & TLI & CFI & SRMR & RMSEA \\
\hline $\begin{array}{l}\text { Guiding principle } \\
\text { (One-factor) }\end{array}$ & 764.122 & 14 & 32160.41 & 0.814 & 0.876 & 0.065 & 0.166 \\
$\begin{array}{l}\text { Trigger } \\
\text { (Two-factor) }\end{array}$ & 763.104 & 13 & 32166.97 & 0.799 & 0.876 & 0.065 & 0.172 \\
$\begin{array}{l}\text { Trigger } \\
\text { (Three-factor) }\end{array}$ & 735.288 & 13 & 32139.16 & 0.807 & 0.88 & 0.073 & 0.169 \\
$\begin{array}{l}\text { Actor } \\
\text { (Two-factor) }\end{array}$ & 358.742 & 13 & 31762.61 & 0.908 & 0.943 & 0.033 & 0.117 \\
$\begin{array}{l}\text { Actor } \\
\text { (Three-factor) }\end{array}$ & 138.179 & 11 & 31557.198 & 0.96 & 0.979 & 0.027 & 0.077 \\
\hline
\end{tabular}

Source: Own calculations. Link to data: https://doi.org/10.7802/2033.

Notes: Widely used cut-off points for incremental fit-indicies: TLI>0.95; CFI>0.95; SRMR<0.05, RMSEA>0.05 (based on Hu \& Bentler, 1999).

Thus, the final factor solution captures three underlying factors: solidarity with collective actors, social security solidarity and healthcare solidarity (Figure 3). The factors for the three concepts were highly and positively correlated. A high score (i.e. high support) for a certain form of solidarity results in a high score for another form and vice versa. The strong correlation between the factors indicated that incorporating them under the umbrella 
term European solidarity was a valid choice. However, since these are distinct forms of solidarity, there will also be different mechanisms that influence each of these factors.

All in all, the confirmatory factor analysis highlighted several important findings. First, attitudes towards European solidarity are not encapsulated by one single factor. Second, the trigger for European solidarity does not play a defining role in shaping attitudes. Instead, we could distinguish attitudes from one another by looking at whether solidarity targeted collective actors (i.e. member states) and individuals (i.e. other Europeans). Lastly, solidarity with individuals can be further broken down into healthcare-related attitudes and support for vulnerable groups (i.e. the elderly and the unemployed).

Figure 3: Final factor solution of CFA models with standardized coefficients

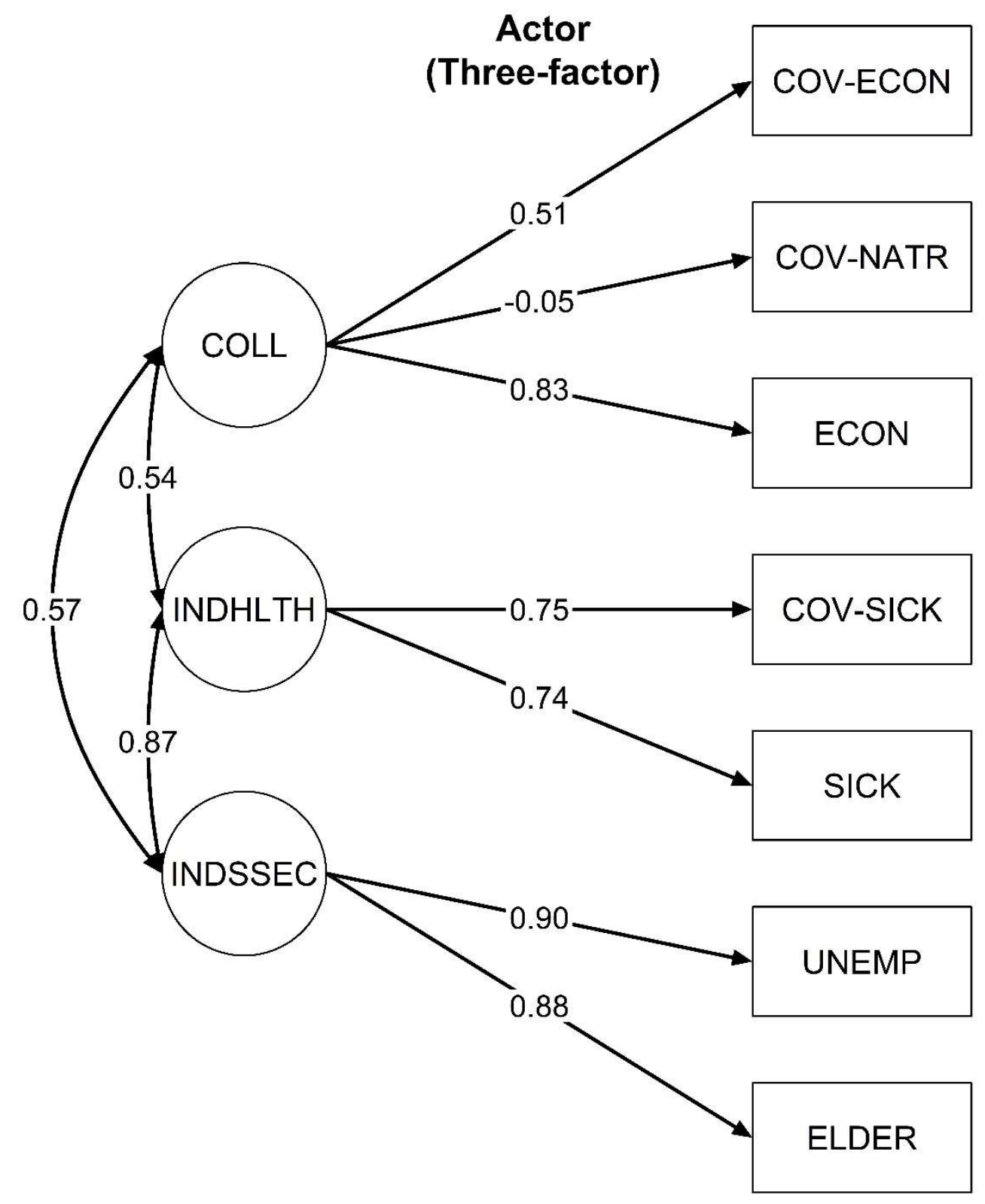

\begin{tabular}{|c|c|c|c|c|c|c|c|}
\hline Model & $\chi^{2}$ & df & BIC & TLI & CFI & SRMR & RMSEA \\
\hline $\begin{array}{c}\text { Actor } \\
\text { (Three-factor) }\end{array}$ & 138.179 & 11 & 31557.2 & 0.96 & 0.979 & 0.027 & 0.077 \\
\hline
\end{tabular}




\subsection{Salience of the factor structure}

A final step when seeking to verify the identified factor structure is to test whether the structure is salient across social groups. This means examining whether the final model can be generalized to the subgroups of the survey sample. To this end, we employed multigroup CFA. The method investigates whether the factor weights correspond across the designated groups. As previously discussed, we tested this for gender, level of education, identity and cohorts. This analysis also indicated whether our results were sensitive to the social groups that our survey oversamples, namely highly educated people and women.

Table 3 displays the model fit indices of the multi-group confirmatory factor analysis (MGCFA) models by sets of subgroups. For each set of subgroups (e.g. gender is divided into two subgroups: men and women, for an overview of subgroups see Table 1), we tested a configural and metric invariant model. The configural model allowed all the factor weights to be determined freely in each subgroup and served as the baseline model. The metric invariant model constrained the factor weights for corresponding items to be equal across all subgroups. The metric invariant model needed to estimate considerably fewer parameters and was a more parsimonious model. Thus, if the metric invariant model for a certain subgroup set was not significantly worse than the configural model, we could regard it as evidence that the factors' meaning did not significantly differ across the subgroups and that the structure is salient.

Table 3: Overview of MGCFA models

\begin{tabular}{lccccccc}
\hline \multicolumn{1}{c}{ Model } & $\chi^{\mathbf{2}}$ & df & BIC & TLI & CFI & SRMR & RMSEA \\
\hline $\begin{array}{l}\text { Gender } \\
\text { Configural }\end{array}$ & 159.541 & 22 & 31578.127 & 0.957 & 0.977 & 0.033 & 0.08 \\
$\begin{array}{l}\text { Metric invariant } \\
\text { Education }\end{array}$ & 167.099 & 26 & 31555.381 & 0.962 & 0.977 & 0.035 & 0.075 \\
$\begin{array}{l}\text { Configural } \\
\text { Metric invariant }\end{array}$ & 137.553 & 22 & 31341.839 & 0.963 & 0.98 & 0.032 & 0.073 \\
$\begin{array}{l}\text { Identity } \\
\text { Configural }\end{array}$ & 159.645 & 26 & 31333.627 & 0.963 & 0.977 & 0.043 & 0.073 \\
$\begin{array}{l}\text { Metric invariant } \\
\text { Birth cohort }\end{array}$ & 161.931 & 33 & 31306.254 & 0.959 & 0.978 & 0.032 & 0.078 \\
Configural & 170.502 & 41 & 31254.216 & 0.967 & 0.978 & 0.034 & 0.07 \\
Metric invariant & 192.722 & 41 & 31336.441 & 0.96 & 0.974 & 0.041 & 0.075 \\
\hline
\end{tabular}

Source: Own calculations. Link to data: https://doi.org/10.7802/2033.

As summarized in Table 3, the baseline models exhibited good model fits. Values for TLI, $\mathrm{CFI}$ and SRMR were all also within the desired cut-off points. More importantly, comparing the configural and metric invariant model solutions led us to conclude that the metric invariant model was preferable to the configural models in all of our MGCFAs. While the TLI, CFI and SRMR did not differ substantially, the Bayesian information criterion (BIC) indicated that the additional model complexity did not worsen the model fit considerably. Overall, the multi-group analysis indicated that the three-factor solution (see Figure 3 ) has a structure that is robust across major socio-demographic groups and that the forms of European solidarity are indeed persistent across gender, educational levels, cohort groups and, most importantly, identification with the European project. 


\section{Discussion}

Due to the COVID-19 pandemic, policymakers face the question of how willing European citizens are to support one another and in what respects. This study uses this period and the salient topic of European solidarity to investigate the structure underlying European solidarity and how different forms of European solidarity are related. The fundamental insight of the current study is that European solidarity is not comprised of a single factor and that social scientists must consider the complex nature of European solidarity when analysing the issue. This study underlines that differentiating between individual actors or collective actors at the member-state level as recipients of support is particularly relevant. This empirical contribution extends the theoretical insights of previous scholars and shows the complexity of European solidarity during the COVID-19 pandemic. Furthermore, it highlights how European solidarity related to the COVID-19 pandemic is strongly interrelated to other forms of solidarity.

Substantively, our empirical study has confirmed the multidimensionality of European solidarity. European solidarity related to the COVID-19 pandemic fits with other forms of European solidarity. Thus, we rejected $\mathrm{H} 1$, which hypothesized that triggers would be a decisive factor in structuring European solidarity and that European solidarity related to the COVID-19 pandemic is a form of European solidarity on its own. Moreover, we rejected $\mathrm{H} 3$, because the items did not load onto one single risk-sharing factor. Although we only formally tested one dimension of the guiding principles (and did not investigate items related to redistributive support), this sufficed to reject $\mathrm{H} 3$, which suggested that European solidarity would be structured by the guiding principle behind solidarity. Yet, even if the surveyed items had loaded on to one factor, we could have only partially verified $\mathrm{H} 3$, as the study lacks information about whether redistributive items come together to form a second single factor. Thus, the analysis supports $\mathrm{H} 2$ : forms of European solidarity seem to be divided based on the type of actor to whom solidarity is extended. Moreover, we identified that this structure of European solidarity is consistent across various socio-economic groups; therefore, $\mathrm{H} 4$ is supported as well.

Further important results include the finding that the type of actor is not the sole factor structuring patterns of European solidarity according to the final model: solidarity with individual actors is further divided into healthcare solidarity and social security solidarity. We interpret this additional distinction of support for individual actors into the subtopics of healthcare and support of vulnerable groups as evidence that European solidarity is partially shaped by the public discourse and framing. Such findings suggest that European solidarity has a dynamic structure and that there is still much to explore regarding the underlying patterns of solidarity. Furthermore, the respondents also emphasized the importance of national responsibility in the pandemic. The support rates for the item regarding countries' duty to halt the spread of the virus indicates the importance of responsibility when extending solidarity. In other words, holding member states accountable for their own state is an important feature complementing the extension of solidarity to collective actors.

Of course, our study has some limitations. As discussed, we rely on a convenience sample and replications are needed to verify our insights. Although the multi-group CFA confirms that the results are similar across the considered socio-economic groups, we cannot rule out the possibility that selection based of other unobserved variables would have yielded different results due to unobserved confounders. Likewise, our results are based on a purely German sample and should only be generalized to other settings with caution. Therefore, replicating our findings in other nations would be an interesting complement to our work. This is necessary to ascertain that the results were not confounded by the public discourse taking place in Europe and Germany at the time of sampling. Likewise, the cross-sectional sample prevents us from drawing any conclusions about the durability and 
possible changes of the results during the course of the crisis. As people and governments adapt to the pandemic on an almost daily basis, longitudinal studies would be helpful to investigate whether and how the domains change in relation to one another.

\section{References}

Alon, T., Doepke, M., Olmstead-Rumsey, J. \& Tertilt, M. (2020). The impact of COVID-19 on gender equality. Cambridge, MA.

Anderson, M., Mckee, M. \& Mossialos, E. (2020). COVID-19 exposes weaknesses in European response to outbreaks. $B M J, 368, \mathrm{~m} 1075$.

Bauer, A. \& Weber, E. (2020). The unemployment impact of corona containment measures in Germany (IAB Discussion Paper No. 202016). Nürnberg.

Baute, S., Meuleman, B., Abts, K. \& Swyngedouw, M. (2018). Measuring attitudes towards social Europe: A multidimensional approach. Social Indicators Research, 137, 353-378.

Brown, T. A. (2015). Confirmatory factor analysis for applied research (2nd ed.). New York: Guilford Press.

Brown, T. A. \& Moore, T. M. (2015). Confirmatory factor analysis. In R. H. Hoyle (Ed.). Handbook of Structural Equation Modeling (361-379). New York, London: The Guilford Press.

Cheung, G. W. \& Rensvold, R. B. (2002). Evaluating goodness-of-fit indexes for testing measurement invariance. Structural Equation Modeling: A Multidisciplinary Journal, 9(2), 233-255.

Ciornei, I. \& Recchi, E. (2017). At the source of European solidarity: Assessing the effects of cross-border practices and political attitudes. Journal of Common Market Studies, 55(3), 468-485.

Coibion, O., Gorodnichenko, Y. \& Weber, M. (2020). The Cost of the COVID-19 crisis: Lockdowns, macroeconomic expectations, and consumer spending (NBER Working Paper No. 27141). Cambridge, MA.

Collins, C., Landivar, L. C., Ruppanner, L. \& Scarborough, W. J. (2020). COVID-19 and the gender gap in work hours. Gender, Work, and Organization, 28(S1), 101-112.

Czymara, C. S., Langenkamp, A. \& Cano, T. (2020). Cause for concerns: gender inequality in experiencing the COVID-19 lockdown in Germany. European Societies, 23(sup1), 68-S81.

Daniele, G. \& Geys, B. (2015). Public support for European fiscal integration in times of crisis. Journal of European Public Policy, 22(5), 650-670. 
Dernberger, B. \& Pepin, J. (2020). Gender flexibility, but not equality: Young adults' division of labor preferences. Sociological Science, 7, 36-56.

Díez Medrano, J., Ciornei, I. \& Apaydin, F. (2019). Explaining solidarity in the European Union. In E. Recchi, F. Apaydin, R. Barbulescu, A. Favell, M. Braun, \& I. Ciornei (Eds.). Everyday Europe: Social Transnationalism in an Unsettled Continent (137-170). Bristol: Policy Press.

Epskamp, S. (2019). semPlot: Path Diagrams and visual analysis of various SEM packages' output: $R$ package version 1.1.2. Retrieved from: https://CRAN.R-project.org/ package $=$ semPlot.

Espinosa, M. P. \& Kovářík, J. (2015). Prosocial behavior and gender. Frontiers in Behavioral Neuroscience, 9, 88.

European Commission (2020a, May 27). Europe's moment: Repair and prepare for the next generation [Press release]. Brussels. Retrieved from: https://ec.europa.eu/commission/ presscorner/detail/en/IP_20_940.

European Commission (2020b). Coronavirus: European solidarity in action. Retrieved from: https://ec.europa.eu/commission/presscorner/detail/en/FS_20_563.

European Parliament (2020a, March 27). Coronavirus: EU countries to get help from Solidarity Fund [Press release]. Brussels. Retrieved from: https://www.europarl.europa.eu/ news/en/headlines/society/20200323STO75625/coronavirus-eu-countries-to-get-helpfrom-solidarity-fund.

European Parliament (2020b, July 29). COVID-19: The EU plan for the economic recovery [Press release]. Brussels. Retrieved from: https://www.europarl.europa.eu/ news/en/headlines/economy/20200513STO79012/covid-19-the-eu-plan-for-theeconomic-recovery.

Ferrera, M. \& Pellegata, A. (2019). Can economic and social Europe be reconciled? Masselite differences in attitudes toward integration and solidarity. Milan. Retrieved from: https://www.resceu.eu/publications/working-papers/wp-4-2019-can-economic-and-social-europe-be-reconciled-mass-elite-differences-in-attitudes-toward-integration-andsolidarity\%E2\%80\%9D.html.

Genschel, P. \& Hemerijck, A. (2018). Solidarity in Europe (Policy Brief No. Issue 2018/01). Fiesole: EUI School of Transnational Governance. Retrieved from: https://cadmus.eui.eu/handle/1814/53967.

Gerhards, J. (2020). Europäische Solidarität in der Corona-Krise [European solidarity in the corona crisis] (BSSE Working Paper No. 41). Berlin.

Gerhards, J., Ignácz, Z. S., Kley, F. K., Lengfeld, H. \& Priem, M. (2019b). How strong is European welfare solidarity? Results from a comparative survey conducted in 13 EU Member 
States. In M. Heidenreich (Ed.). Horizontal Europeanisation: The Transnationalisation of Daily Life and Social Fields in Europe (39-62). London: Routledge.

Gerhards, J., Lengfeld, H., Ignácz, Z. S., Kley, F. K. \& Priem, M. (2019a). European solidarity in times of crisis: Insights from a thirteen-country survey. Abingdon: Routledge.

Gerhards, J., Lengfeld, H., Soler Gallart, M., Ignácz, Z. S., Kley, F. K., Priem, M. \& Ramos, R. ([unpublished]). Transnational European solidarity survey [Codebook]: tbd.

Hainmueller, J. \& Hiscox, M. J. (2007). Educated preferences: Explaining attitudes toward immigration in Europe. International Organization, 61(2), 399-442.

Hallquist, M. N. \& Wiley, J. F. (2018). MplusAutomation: An R package for facilitating largescale latent variable analyses in Mplus. Structural Equation Modeling: A Multidisciplinary Journal, 25(4), 621-638.

Häusermann, S., Kurer, T. \& Schwander, H. (2015). High-skilled outsiders? Labor market vulnerability, education and welfare state preferences. Socio-Economic Review, 13(2), 235-258.

Hooghe, M. \& Verhaegen, S. (2017). The Democratic Legitimacy of EU Institutions and Support for Social Policy in Europe. In F. Vandenbroucke, C. Barnard, \& G. d. Baere (Eds.). A European social union after the crisis (120-139). Cambridge: Cambridge University Press.

Hu, L. \& Bentler, P. M. (1999). Cutoff criteria for fit indexes in covariance structure analysis: Conventional criteria versus new alternatives. Structural Equation Modeling: A Multidisciplinary Journal, 6(1), 1-55.

Ignácz, Z. S. (2019). Contrasting generalized and policy attitudes toward social Europe: Understanding the discrepancies (BSSE Working Paper No. 39). Berlin. Retrieved from: https://www.polsoz.fu-berlin.de/soziologie/arbeitsbereiche/makrosoziologie/arbeitspapiere/BSSE-Nr_-39.html.

Jæger, M. M. \& Blaabæk, E. H. (2020). Inequality in learning opportunities during COVID19: Evidence from library takeout. Research in Social Stratification and Mobility, 68, 100524.

Khurshid, A. \& Khan, K. (2020). How COVID-19 shock will drive the economy and climate? A data-driven approach to model and forecast. Environmental Science and Pollution Research, 28, 2948-2958.

Kline, R. B. (2011). Principles and practice of structural equation modeling (3. ed.). New York: Guilford Press. 
Kreyenfeld, M., Zinn, S., Entringer, T., Goebel, J., Grabka, M. M., Graeber, D., Kroh, M., Kröger, H., Kühne, S., Liebig, S., Schröder, C., Schupp, J. \& Seebauer, J. (2020). Coronavirus \& care: How the coronavirus crisis affected fathers' involvement in Germany (SOEPpapers on Multidisciplinary Panel Data Research No. 1096). Berlin.

Kuhn, T. \& Stoeckel, F. (2014). When European integration becomes costly: the euro crisis and public support for European economic governance. Journal of European Public Policy, 21(4), 624-641.

Langenkamp, A. (2020). Corona survey: GESIS Data Archive. Retrieved from: https://doi.org/10.7802/2033.

Lewis, T. F. (2017). Evidence regarding the internal structure: Confirmatory factor analysis. Measurement and Evaluation in Counseling and Development, 50(4), 239-247.

Mau, S. (2005). Democratic demand for a social Europe? Preferences of the European citizenry. International Journal of Social Welfare, 14(2), 76-85.

Mau, S. \& Burkhardt, C. (2009). Migration and welfare state solidarity in western Europe. Journal of European Social Policy, 19(3), 213-229.

Möhring, K., Naumann, E., Reifenscheid, M., Wenz, A., Rettig, T., Krieger, U., Friedel, S., Finkel, M., Cornesse, C. \& Blom, A. G. (2020). The COVID-19 pandemic and subjective wellbeing: longitudinal evidence on satisfaction with work and family. European Societies, 23(sup1), 601-617.

Muthén, L. \& Muthén, B. (1998-2019). Mplus user's guide eighth edition (Version 8.4) [Computer software]. Los Angeles, California.

Peterson, R. A. \& Merunka, D. R. (2014). Convenience samples of college students and research reproducibility. Journal of Business Research, 67(5), 1035-1041.

Pettersen, P. A. (1998). The welfare state: The security dimension. In O. Borre \& E. Scarbrough (Eds.). The Scope of Government (198-233). Oxford: Oxford University Press.

Pfefferbaum, B. \& North, C. S. (2020). Mental health and the COVID-19 pandemic. The New England Journal of Medicine, 383(6), 510-512.

R Core Team (2019). R: A Language and environment for statistical computing (Version 3.6.1) [Computer software].

Reinl, A.-K. (2020). Conceptualizing transnational solidarity. Measuring European solidarity workshop, 27.-28.01.2020, GESIS - Leibniz-Institut für Sozialwissenschaften, Köln.

Roller, E. (1998). The welfare state: The equality dimension. In O. Borre \& E. Scarbrough (Eds.). The Scope of Government (165-197). Oxford: Oxford University Press. 
Saunders, M. (2020, September). The economy and COVID-19: Looking back and looking forward. Bank of England. Bank of England Online Webinar, London. Retrieved from: https://www.bankofengland.co.uk/-/media/boe/files/speech/2020/the-economy-andcovid-19-looking-back-and-looking-forward-speech-by-michael-saunders.pdf.

Schmid, G. (2020). Beyond European unemployment insurance. Less moral hazard, more moral assurance? Transfer: European Review of Labour and Research, 26(4), 465-480.

Sibley, C. G., Greaves, L. M., Satherley, N., Wilson, M. S., Overall, N. C., Lee, C. H. J., Milojev, P., Bulbulia, J., Osborne, D., Milfont, T. L., Houkamau, C. A., Duck, I. M., Vickers-Jones, R. \& Barlow, F. K. (2020). Effects of the COVID-19 pandemic and nationwide lockdown on trust, attitudes toward government, and well-being. American Psychologist, 75(5), 618-630.

Sülün, D. (2020). The weakness of European integration in response to COVID-19 pandemic: The Question of European Solidarity. Contemporary Macedonian Defense / Sovremena Makedonska Odbrana, 20(38), 57-68.

Tidey, A. (2020, March 28). More French COVID-19 patients flown to Germany and Switzerland. Euronews.

Vasilopoulou, S. \& Talving, L. (2020). Poor versus rich countries: a gap in public attitudes towards fiscal solidarity in the EU. West European Politics, 43(4), 919-943.

Voicu, B., Bartolome Peral, E., Rusu, H., Rosta, G., Comșa, M., Vasile, O.-M., Coromina, L. \& Tufis, C. (2020). COVID-19 and orientations towards solidarity: the cases of Spain, Hungary, and Romania. European Societies, 23(sup1), 887-904.

Wallaschek, S. \& Ziegler, F. L. (2021). Making sense of the 'new normal': The COVID-19 crisis in the communication of the prime ministers of Ireland and New Zealand. Culture, Practice \& Europeanization, 6(1), 112-134.

Wachtler, B., Michalski, N., Nowossadeck, E., Diercke, M., Wahrendorf, M., SantosHövener, C., Lampert, T. \& Hoebel, J. (2020). Socioeconomic inequalities and COVID-19 A review of the current international literature. Journal of Health Monitoring, 5(S7), 3-17.

Wickham, H. (2016). ggplot2: Elegant graphics for data analysis (2nd ed.). Cham: Springer.

Witkowska, D. (2013). Gender disparities in the labor market in the EU. International Advances in Economic Research, 19(4), 331-354. 


\section{Appendix}

Table A1: Overview of items

\begin{tabular}{|c|c|c|c|c|}
\hline Item & Item wording & Trigger & Actor & Guiding principle \\
\hline ELDER & $\begin{array}{l}\text { The European Union should guarantee a decent standard of } \\
\text { living for the elderly in the EU }\end{array}$ & Welfare state & Individual & Risk-sharing \\
\hline SICK & $\begin{array}{l}\text { The European Union should guarantee access to healthcare } \\
\text { for everyone in the EU }\end{array}$ & Welfare state & Individual & Risk-sharing \\
\hline UNEMP & $\begin{array}{l}\text { The European Union should guarantee a decent standard of } \\
\text { living for the unemployed in the EU }\end{array}$ & Welfare state & Individual & Risk-sharing \\
\hline ECON & $\begin{array}{l}\text { In times of crisis, EU member states facing severe economic } \\
\text { difficulties should receive financial help }\end{array}$ & Fiscal & Collective & Risk-sharing \\
\hline COV-SICK & $\begin{array}{l}\text { The European Union should guarantee access to healthcare } \\
\text { for everyone in the EU who is ill because of the novel } \\
\text { coronavirus }\end{array}$ & COVID-19 related & Individual & Risk-sharing \\
\hline COV-NATR & $\begin{array}{l}\text { During the coronavirus pandemic, every member state of the } \\
\text { European Union is responsible for the spread of the virus in } \\
\text { their own country }\end{array}$ & COVID-19 related & Collective & Risk-sharing \\
\hline COV-ECON & $\begin{array}{l}\text { During the coronavirus pandemic, EU member states should sup- } \\
\text { port each other beyond financial means }\end{array}$ & COVID-19 related & Collective & Risk-sharing \\
\hline
\end{tabular}

Source: Own description. Link to data: https://doi.org/10.7802/2033. 
Table A2: Correlation matrix of items

\begin{tabular}{crrrrrrr} 
& ELDER & UNEMP & SICK & COV-SICK & ECON & COV-NATR & COV-ECON \\
\hline ELDER & 1 & & & & & & \\
UNEMP & 0.715 & 1 & & & & & \\
SICK & 0.685 & 0.635 & 1 & & & & \\
COV-SICK & 0.641 & 0.612 & 0.77 & 1 & & 1 & \\
ECON & 0.379 & 0.473 & 0.395 & 0.431 & 1 & \\
COV-NATR & -0.023 & -0.089 & -0.046 & -0.038 & -0.054 & 0.042 & 1 \\
COV-ECON & 0.251 & 0.326 & 0.297 & 0.345 & 0.541 & &
\end{tabular}

